\title{
Pengelompokkan Kabupaten/Kota Di Sulawesi Berdasarkan Indikator Pendidikan Menggunakan Analisis Klaster Average Linkage Dan Median Linkage
}

\section{(District/City Clustering In Sulawesi Based On Education Indicators Using Average Linkage Cluster And Median Linkage Analysis)}

\author{
Eka Oktavianty ${ }^{1^{*}}$, Junaidi ${ }^{1}$ dan Lilies Handayani ${ }^{1}$ \\ ${ }^{1}$ Program Studi Statistika, Jurusan Matematika, Fakultas MIPA, Universitas Tadulako, Jl. Soekarno Hatta Km 9 Tondo \\ Palu Sulawesi Tengah 94118.
}

Keywords: Educational Indicators, Cluster Analysis, Average Linkage, Median Linkage, Standard Deviation Ratio.

Keywords: Indikator Pendidikan, Analisis Klaster, Average Linkage, Median Linkage, Rasio Simpangan Baku.

* Coresponding Author : ekaoktavianty97@gmail.com

\begin{abstract}
Education is important to improve the quality of human resources, but the important issue that often arises is the problem of the low quality of education and equitable distribution of education. Measuring instruments used to see how well the quality of education is an indicator of education. To find out the ranking of education or the characteristics of the level of education, the grouping is done based on educational indicators using cluster analysis. Cluster analysis is a multivariate technique that classifies objects into different groups between one group and another group. In this study, the methods will be used average linkage and median linkage in classifying Regencies /Cities in Sulawesi based on education indicators. The results of the analysis showed that the median linkage obtained a standard deviation ratio value of 0.061 smaller than the standard deviation ratio average linkage value of 0.078 . The method that has the smallest ratio is the method with the best performance. So that grouping City Districts in Sulawesi based on education indicators in 2017 is better to use the median linkage.
\end{abstract}

\begin{abstract}
Abstrak
Pendidikan merupakan hal yang penting untuk meningkatkan kualitas sumber daya manusia, akan tetapi permasalahan yang sering muncul adalah isu tentang rendahnya mutu pendidikan dan pemerataan pendidikan. Alat ukur yang digunakan untuk melihat seberapa baik kualitas pendidikan adalah indikator pendidikan. Untuk mengetahui pemerataan pendidikan atau karakteristik tingkat pendidikan maka dilakukan pengelompokkan berdasarkan indikator pendidikan menggunakan analisis klaster. Analisis klaster adalah salah satu teknik multivariat yang mengklasifikasikan suatu objek-objek ke dalam kelompok yang berbeda antara kelompok satu dengan kelompok lainnya. Pada penelitian ini akan digunakan metode average linkage dan median linkage dalam mengelompokkan Kabupaten/Kota di Sulawesi berdasarkan indikator pendidikan. Hasil dari analisis menunjukkan bahwa median linkage memperoleh nilai rasio simpangan baku sebesar 0,061 lebih kecil dibandingkan dengan nilai rasio simpangan baku average linkage yakni 0,078 . Metode yang mempunyai rasio terkecil merupakan metode dengan kinerja terbaik. Sehingga pengelompokkan Kabupaten/Kota di Sulawesi berdasarkan indikator pendidikan tahun 2017 lebih baik menggunakan median linkage.
\end{abstract}




\section{Latar Belakang}

Menurut Supranto (2004) analisis multivariat merupakan analisis yang digunakan untuk memahami struktur data yang melibatkan lebih dari satu variabel atau teknik analisis yang melibatkan banyak variabel. Multivariat terbagi dua, yaitu analisis dependensi dan analisis interdependensi. Analisis klaster termasuk dalam analisis multivariat interdependensi atau saling ketergantungan (Gudono, 2015).

Analisis klaster adalah salah satu teknik multivariat yang mengklasifikasi suatu objek-objek ke dalam kelompok yang berbeda antara kelompok satu dengan kelompok lainnya (Goreti dkk, 2016). Analisis klaster dibagi dua yaitu metode hierarki dan nonhierarki. Klaster hierarki memulai pengelompokkan dengan dua atau lebih objek yang mempunyai kesamaan paling dekat dan kemudian diteruskan keobjek yang mempunyai kedekatan kedua, demikian seterusnya hingga klaster membentuk semacam pohon dimana ada tingkatan yang jelas antar objek. Alat yang membantu memperjelas proses hierarki disebut dendogram, dendogram merupakan representasi visual dari langkah analisis klaster yang menunjukkan bagaimana klaster terbentuk dan nilai koefisien jarak pada setiap langkah (Sitepu dkk, 2011).

Metode klaster hierarki diantaranya yaitu single linkage, complete linkage, average linkage, centroid linkage, ward linkage, dan median linkage (Goreti dkk, 2016). Keuntungan penggunaan metode hierarki dalam analisis klaster adalah mempercepat pengolahan dan menghemat waktu karena data yang diinputkan akan membentuk hierarki atau membentuk tingkatan sendiri sehingga mempermudah dalam penafsiran, namun kelemahan dalam metode ini adalah seringnya terdapat kesalahan pada data outlier, perbedaan ukuran jarak yang digunakan, dan terdapatnya variabel yang tidak relevan (Hardius dan Nurdin 2013).

Penelitian terkait dengan klaster hierarki dilakukan oleh (Fadliana dan Rozi, 2015) menggunakan agglomerative hierarchical clustering pada data kualitas pelayanan keluarga berencana. Pada penelitiannya, berdasarkan hasil uji validitas klaster metode average linkage memberikan solusi klaster yang lebih baik dibandingkan dengan metode single linkage, complete linkage dan ward. Penelitian selanjutnya oleh (Ningsih dkk, 2016) menggunakan metode complete linkage dan average linkage pada data produksi palawija menghasilkan metode average linkage merupakan metode terbaik berdasarkan hasil perhitugan rasio simpangan baku.
Pendidikan merupakan hal yang penting untuk meningkatkan kualitas sumber daya manusia, pentingnya pendidikan bagi manusia diantaranya yaitu mampu memberikan ilmu pengetahuan yang luas bagi manusia dan pendidikan merupakan salah satu pilar utama dalam proses peningkatan kemampuan dan daya saing suatu bangsa, sehingga pembangunan pendidikan sangat diperlukan. Pembangunan pendidikan merupakan investasi dalam meningkatkan kualitas sumber daya manusia yang berperan penting dalam meningkatkan pertumbuhan ekonomi dan menurunkan tingkat kemiskinan serta pengangguran (BPS Indonesia, 2018).

Pentingnya peran pendidikan terhadap kemajuan bangsa, pengukuran dan penghitungan indikatorindikator pendidikan perlu dilakukan untuk melihat sejauh mana pemerataan pendidikan. Agar dapat mengetahui pemerataan pendidikan atau karekteristik tingkat pendidikan maka dilakukan pengelompokkan menggunakan analisis klaster. Berdasarkan uraian di atas, pada penelitian ini akan dilakukan pengelompokkan Kabupaten/Kota di Sulawesi berdasarkan indikator pendidikan menggunakan metode klaster average linkage dan median linkage.

\section{Bahan dan Metode}

Data yang digunakan dalam penelitian ini merupakan data sekunder yang diperoleh dari Badan Pusat Statistik (BPS) provinsi-provinsi di Sulawesi yaitu data indikator pendidikan Kabupaten/Kota di Sulawesi tahun 2017. Jumlah Provinsi yang digunakan sebanyak 6 Provinsi dan 81 Kabupaten/Kota dengan 11 variabel. Berikut ini merupakan variabel-variabel yang digunakan dalam penelitian, yaitu:

1. Angka Partisipasi Sekolah Umur 7-12

2. Angka Partisipasi Sekolah Umur 13-15

3. Angka Partisipasi Sekolah Umur 16-18

4. Angka Partisipasi Kasar Umur 7-12

5. Angka Partisipasi Kasar Umur 13-15

6. Angka Partisipasi Kasar Umur 16-18

7. Angka Partisipasi Murni Umur 7-12

8. Angka Partisipasi Murni Umur 13-15

9. Angka Partisipasi Murni Umur 16-18

10.Belum/Tidak Pernah Sekolah

11.Rata-rata Lama Sekolah

Metode yang digunakan pada penelitian ini adalah analisis klaster metode average linkage dan median linkage. Langkah-langkah analisis yang akan digunakan pada penelitian ini adalah sebagai berikut: 
1. Mengumpulkan data, yang diambil dari web resmi BPS Provinsi di Sulawesi pada tahun 2017

2. Melakukan uji kelayakan data, yaitu sampel harus mewakili populasi dengan dengan melihat nilai KMO atau MSA dan melihat hubungan antar variabel dengan uji Bartlett,untuk mengetahui apakah data terdapat multikolinearitas dengan melihat nilai VIF.

3. Menghitung nilai kemiripan antar objek menggunakan rumus euclidean.

4. Memilih prosedur analisis klaster.

5. Menginterpretasi klaster.

6. Menentukan metode terbaik.

7. Menarik kesimpulan

\section{Hasil dan Pembahasan}

Tujuan dalam penelitian ini untuk memperoleh pengelompokkan dan membandingkan hasil analisis menggunakan klaster average linkage dan median linkage Kabupaten/Kota di Sulawesi berdasarkan indikator pendidikan dan penelitian ini menggunakan software $R$. Berikut merupakan proses pengelompokkan dengan menggunakan average linkage dan median linkage Kabupaten/Kota di Sulawesi Tengah berdasarkan indikator pendidikan.

\section{Uji Multikolinearitas}

Berdasarkan Tabel 1 terlihat bahwa pada variabel $\mathrm{X}_{4}$ sebesar 12.816 dan $X_{7}$ sebesar 15.658 , variabel yang memiliki nilai VIF lebih dari 10 artinya terjadi multikolinearitas,sehingga variabel yang memiliki nilai VIF paling tinggi dihilangkan. Variabel $X_{7}$ dihilangkan maka dilakukan kembali pengujian multikolinearitas. Berdasarkan Tabel 2 terlihat nilai VIF dari semua variabel kurang dari 10 , sehingga dapat disimpulkan tidak terjadi multikolinearitas pada 10 variabel.

\section{Uji Kaiser Meyer Olkin}

Berdasarkan Tabel 3 menunjukkan nilai KMO sebesar $0.622>0.5$, sehingga dapat disimpulkan sampel yang digunakan sudah cukup untuk dianalisis lebih lanjut. Tabel 4 menunjukkan nilai MSA dari semua variabel melebihi 0.5 , artinya setiap variabel layak digunakan.
Tabel 1. Nilai VIF 11 Variabel

\begin{tabular}{|c|c|}
\hline Variabel & VIF \\
\hline X1 & 3.157 \\
X2 & 2.410 \\
X3 & 5.498 \\
X4 & 12.816 \\
X5 & 5.366 \\
X6 & 2.125 \\
X7 & 15.658 \\
X8 & 9.278 \\
X9 & 4.464 \\
X10 & 1.774 \\
X11 & 1.981 \\
\hline
\end{tabular}

Tabel 2. Nilai VIF 10 Variabel

\begin{tabular}{|c|c|}
\hline Variabel & VIF \\
\hline X1 & 3.157 \\
X2 & 2.375 \\
X3 & 5.472 \\
X4 & 2.426 \\
X5 & 5.223 \\
X6 & 2.075 \\
X8 & 7.919 \\
X9 & 4.458 \\
X10 & 1.675 \\
X11 & 1.974 \\
\hline
\end{tabular}

Tabel 3. Nilai KMO

\begin{tabular}{|c|c|}
\hline Kaiser Meyer Olkin & 0.622 \\
\hline \multicolumn{2}{|l|}{ Tabel 4. Nilai MSA } \\
\hline Variabel & MSA \\
\hline $\mathrm{X} 1$ & 0.507 \\
\hline $\mathrm{x} 2$ & 0.735 \\
\hline $\mathrm{X} 3$ & 0.567 \\
\hline$X 4$ & 0.723 \\
\hline$\times 5$ & 0.699 \\
\hline$x 6$ & 0.550 \\
\hline $\mathrm{x} 8$ & 0.577 \\
\hline X9 & 0.643 \\
\hline $\mathrm{X} 10$ & 0.545 \\
\hline $\mathrm{X} 11$ & 0.635 \\
\hline
\end{tabular}

Tabel 5. Nilai Bartlett

\begin{tabular}{|l|c|}
\hline Nilai Bartlett & 484.7 \\
Df & 45 \\
\hline
\end{tabular}




\section{Uji Bartlett}

Uji Bartlett menyatakan hipotesis sebagai berikut (Suliyanto, 2005):

$H_{0}: \rho=I$ (ada korelasi antar variabel)

$H_{1}: \rho \neq I$ (tidak ada korelasi antar variabel)

Keputusan: Tolak $H_{0}$ bila $X_{\text {hitung }}^{2}>X_{\alpha ; 1 / 2 p(p-1)}^{2}$

Berdasarkan Tabel 5 terlihat bahwa nilai Bartlett sebesar 484.7, Derajat bebas sebesar 45, dan chisquare sebesar 61.65 , sehingga disimpulkan bahwa tidak terjadi korelasi antar variabel karena 484.7 > 61.65

\section{Menghitung Nilai Kemiripan}

Kemiripan antar objek dapat diukur dengan menggunakan ukuran jarak. Menentukan nilai kemiripan antar objek menggunakan jarak euclidean karena data indikator pendidikan Kabupaten/Kota di Sulawesi memiliki satuan data yang sama. Perhitungan jarak euclidean menggunakan rumus sebagai berikut:

$$
d_{i j}=\sqrt{\sum_{k=1}^{p}\left(X_{i k}-X_{j k}\right)^{2}}
$$

Sehingga diperoleh nilai kemiripan antar objek berukuran $81 x 81$ sebagai berikut:

$$
\boldsymbol{D}=\left[\begin{array}{ccccc}
0.000 & 14.64 & 17.40 & \cdots & 19.98 \\
14.64 & 0.000 & 11.13 & \cdots & 20.11 \\
17,40 & 11.13 & 0.000 & \cdots & 20.22 \\
\vdots & \vdots & \vdots & \cdots & \vdots \\
27.15 & 17.93 & 16.20 & \cdots & 31.98 \\
20.72 & 16.35 & 14.67 & \cdots & 29.58 \\
\vdots & \vdots & \vdots & \cdots & \vdots \\
19.60 & 20.42 & 14.00 & \cdots & 18.09 \\
\vdots & \vdots & \vdots & \cdots & \vdots \\
80.16 & 80.06 & 79.35 & \cdots & 82.75 \\
71.61 & 71.39 & 71.00 & \cdots & 74.29 \\
\vdots & \vdots & \vdots & \cdots & \vdots \\
19.98 & 20.11 & 20.22 & \cdots & 0.000
\end{array}\right]
$$

Tabel 6. Rata-rata Variabel Metode Average Linkage

\begin{tabular}{|c|c|}
\hline Klaster & Rata-rata Variabel \\
\hline 1 & 69.124 \\
2 & 76.309 \\
3 & 64.46 \\
4 & 74.45 \\
5 & 29.884 \\
\hline
\end{tabular}

Tabel 7. Rata-rata Variabel Metode Median Linkage

\begin{tabular}{|c|c|}
\hline Klaster & $\begin{array}{c}\text { Rata-rata } \\
\text { Variabel }\end{array}$ \\
\hline 1 & 70.18 \\
2 & 76.309 \\
3 & 64.46 \\
4 & 75.168 \\
5 & 29.884 \\
\hline
\end{tabular}

\section{Proses Analisis Klaster}

Proses pengelompokkan dilakukan setelah jarak antar variable diukur dengan menggunakan jarak euclidean. Hasil analisis mengindikasikan adanya kedekatan antar objek yang bisa dijadikan panduan objek mana yang memiliki kemiripan karakteristik yang sama. Dua objek dengan karakteristik yang sama digambarkan sebagai dua titik yang posisinya berdekatan, semakin dekat posisi dua buah objek maka semakin mirip dan semakin jauh posisi dua buah titik objek maka semakin berbeda.
Tabel 8. Rasio Metode Average Linkage dan Median Linkage

\begin{tabular}{|c|c|c|}
\hline Rasio & $\begin{array}{c}\text { Average } \\
\text { Linkage }\end{array}$ & $\begin{array}{c}\text { Median } \\
\text { Linkage }\end{array}$ \\
\hline$\frac{S_{w}}{S_{B}}$ & 0.078 & 0.061 \\
\hline
\end{tabular}




\section{Interpretasi Klaster Average linkage dan median linkage}

Berdasarkan Tabel 6, Tabel 7, Gambar 1A dan Gambar 1B diketahui bahwa pengelompokkan Kabupaten/Kota di Sulawesi menjadi 5 klasteryang memiliki jumlah anggota yang berbeda pada masingmasing klaster. Hasil pengklasteran yang telah terbentuk diperoleh kelompok Kabupaten/Kota di Sulawesi berdasarkan indikator pendidikan dengan tingkat atau kualitas pendidikan yang sangat baik hingga sangat kurang baik berturut-turut adalah sebagai berikut:

1. Klaster 5 yang beranggotakan 1 Kabupaten/Kota dengan tingkat atau kualitas pendidikan yang sangat baik.

2. Klaster 3 yang beranggotakan 13 Kabupaten/Kota dengan tingkat atau kualitas pendidikan yang baik.

3. Klaster 1 yang beranggotakan 65 Kabupaten/Kota dengan tingkat atau kualitas pendidikan yang cukup baik.

4. Klaster 4 yang beranggotakan 1 Kabupaten/Kota dengan tingkat atau kualitas pendidikan yang

A

Cluster Dendrogram

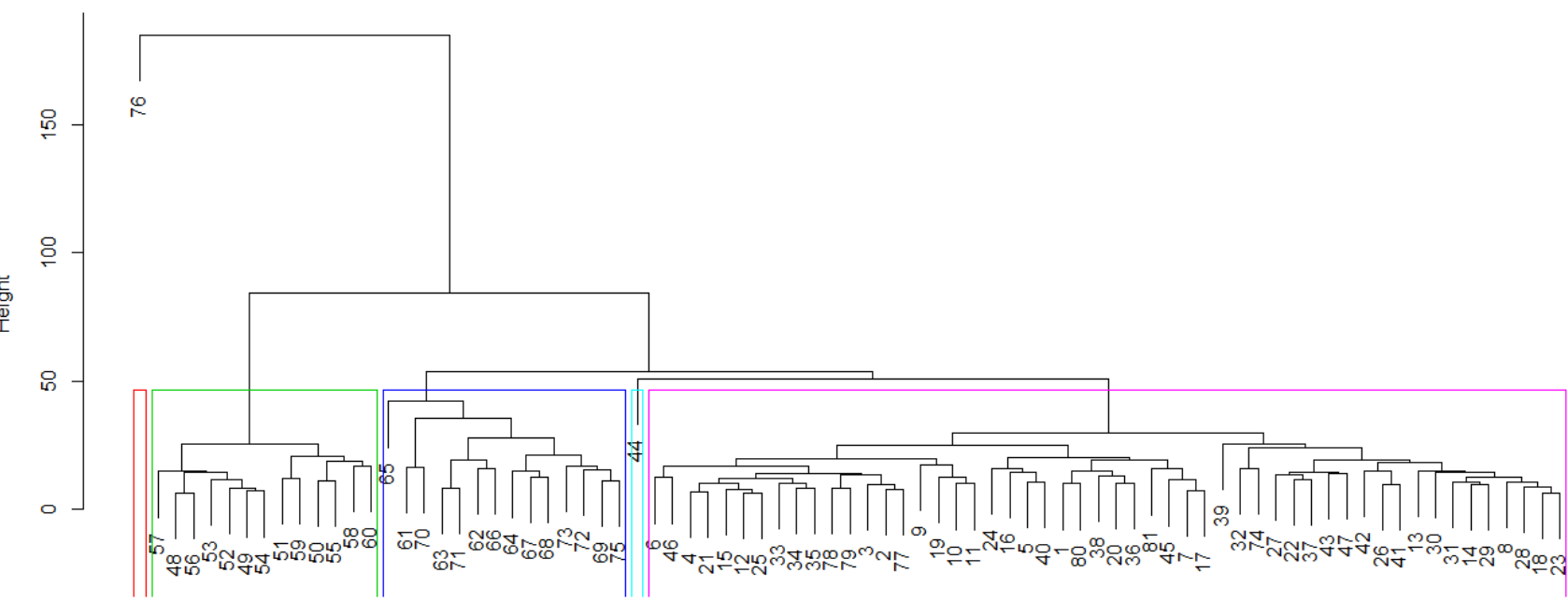

hclust (" "average")

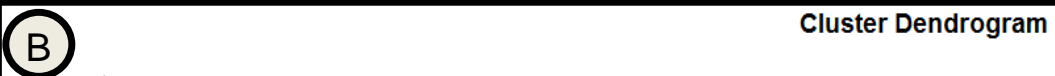

B




kurang baik.

5. Klaster 2 yang beranggotakan 1 Kabupaten/Kota dengan tingkat atau kualitas pendidikan yang sangat kurang baik.

\section{Penentuan Metode Terbaik}

Setelah terbentuk 5 klaster dari metode average linkage dan median linkage, selanjutnya penentuan metode yang menghasilkan klaster terbaik. Pengecekan dilakukan menggunakan simpangan baku dalam klaster dan simpangan baku antar klaster.

1. Simpangan Baku Dalam Klaster

Perhitungan nilai simpangan baku dalam klaster metode average linkage, sebagai berikut:

$$
\begin{aligned}
& S_{W}=K^{-1} \sum_{k=1}^{K} S_{k} \\
& S_{W}=5^{-1}\left(s_{1}+s_{2}+s_{3}+s_{4}+s_{5}\right) \\
& S_{W}=\frac{\left(s_{1}+s_{2}+s_{3}+s_{4}+s_{5}\right)}{5} \\
& S_{W}=\frac{(3.049+0+2.289+2.154+0)}{5} \\
& S_{W}=\frac{7.492}{5}=1.49
\end{aligned}
$$

Perhitungan nilai simpangan baku dalam klaster metode median linkage, sebagai berikut:

$$
\begin{aligned}
& S_{W}=K^{-1} \sum_{k=1}^{K} S_{k} \\
& S_{W}=5^{-1}\left(s_{1}+s_{2}+s_{3}+s_{4}+s_{5}\right) \\
& S_{W}=\frac{\left(s_{1}+s_{2}+s_{3}+s_{4}+s_{5}\right)}{5} \\
& S_{W}=\frac{(3.589+0+2.289+0+0)}{5} \\
& S_{W}=\frac{5.878}{5}=1.18
\end{aligned}
$$

\section{Simpangan Baku Antar Klaster}

$$
S_{B}=\left[(K-1)^{-1} \sum_{k=1}^{K}\left(\bar{X}_{k}-\bar{X}\right)^{2}\right]^{1 / 2}
$$

Perhitungan nilai simpangan baku antar klaster metode average linkage, sebagai berikut:

$$
\begin{aligned}
S_{B} & =\left(\frac{(69.12-62.838)^{2}+\cdots+(29.85-62.838)^{2}}{5-1}\right)^{1 / 2} \\
S_{B} & =\left(\frac{1446.64}{4}\right)^{1 / 2}=(361.66)^{1 / 2}=19.017
\end{aligned}
$$

Perhitungan nilai simpangan baku antar klaster metode median linkage, sebagai berikut:

$$
S_{B}=\left(\frac{(70.18-63.19)^{2}+\cdots+(29.85-63.19)^{2}}{5-1}\right)^{1 / 2}
$$

$$
S_{B}=\left(\frac{1477.68}{4}\right)^{1 / 2}=(369.42)^{1 / 2}=19.220
$$

Untuk mengetahui kinerja kedua metode atau melihat kualitas pengelompokkan yang terbaik, dilihat berdasarkan nilai rasio terkecil. Berdasarkan Tabel 8 metode median linkage memperoleh nilai rasio sebesar 0.061 lebih kecil dibandingkan dengan rasio average linkage sebesar 0.078. Sehingga dapat disimpulkan pengelompokkan Kabupaten/Kota di Sulawesi berdasarkan indikator pendidikan tahun 2017 lebih baik dengan menggunakan metode median linkage.

\section{Ucapan Terimakasih}

Penulis mengucapkan terima kasih kepada pihak Badan Pusat Statistik Provinsi-Provinsi di Sulawesi yang telah memperkenankan penulis untuk mengambil data mengenai indikator pendidikan.

\section{Daftar Pustaka}

Badan Pusat Statistik Provinsi Sulawesi Barat [BPS Sulawesi Barat]. (2017). Statistik Kesejahteraan Rakyat. Mamuju: BPS Sulawesi Barat.

Badan Pusat Statistik Provinsi Gorontalo [BPS Gorontalo]. (2017). Indikator Pendidikan. Gorontalo: BPS Gorontalo.

Badan Pusat Statistik Indonesia [BPS Indonesia]. (2018). Potret Pendidikan Indonesia. Jakarta: BPS Indonesia.

Badan Pusat Statistik Provinsi Sulawesi Selatan [BPS Sulawesi Selatan]. (2017). Statistik Pendidikan. Makassar: BPS Sulawesi Selatan.

Badan Pusat Statistik Provinsi Sulawesi Tengah [BPS Sulawesi Tengah]. (2017). Statistik Kesejahteraan Rakyat. Palu: BPS Sulawesi Tengah.

Badan Pusat Statistik Provinsi Sulawesi Tenggara [BPS Sulawesi Tenggara]. (2017). Indikator Statistik Kesejahteraan Rakyat. Kendari: BPS Sulawesi Tenggara.

Badan Pusat Statistik Provinsi Sulawesi Utara [BPS Sulawesi Utara]. (2017). Statistik Kesejahteraan Rakyat. Manado: BPS Sulawesi Utara.

Fadliana, A., dan Rozi, F. (2015). Penerapan Agglomerative Hierarchical Clustering untuk Klasifikasi Kabupaten/Kota di Provinsi Jawa Timur Berdasarkan Kualitas Pelayanan Keluarga Berencana. Jurnal Cauchy, 4(1): 25-40.

Goreti, M., Novia, Y., dan Wahyuningsih, S. (2016). Perbandingan Hasil Analisis Cluster dengan Menggunakan Metode Single Linkage dan Metode C-Means.Jurnal Eksponensial, 7(1): 9-16. 
Gudono.(2015). Anlisis Data Multivariat Edisi Empat.Yogyakarta: BPFE.

Hardius, U., dan Nurdin, S.(2013). Aplikasi Teknik Multivariate Riset Pemasaran. Jakarta: Raja Grafindo Persada.

Ningsih, S., Wahyuningsih, S., dan Nasution, Yuki, N. (2016). Perbandingan Kinerja Metode Complete Linkage dan Average linkage dalam Menentukan Hasil Analisis Cluster. Jurnal Sains dan Teknologi, 1(1): 46-50.
Sitepu, R., Irmeilyana., dan Gultom, B. (2011). Analisis Klaster Terhadap Tingkat Pencemaran Udara pada Sektor Industri Di Sumatera Selatan.Jurnal Penelitian Sains, 14(3): 11-17.

Suliyanto. (2005). Analisis Data dalam Aplikasi Pemasaran. Bogor: Penerbit Ghalia Indonesia.

Supranto, J. (2004). Analisis Multivariat Arti dan Interpretasi Edisi Pertama. Jakarta: PT Rineka Cipta. 